\title{
Evolutionary aspects of non-metastatic breast cancer after primary treatment in a sub-Saharan African setting: a 16-year retrospective review at the Douala general hospital, Cameroon
}

Bibiana Ateh Nzeangung ${ }^{1}$, Martin Essomba Biwole ${ }^{1}$, Benjamin Momo Kadia ${ }^{2,3,4^{*}}$, Ndemazie Nkafu Bechem ${ }^{5}$, Christian Akem Dimala ${ }^{6,7,8}$ and Albert Mouelle Sone ${ }^{1}$

\begin{abstract}
Background: Breast cancer has a high case fatality rate in sub-Saharan Africa, and this is chiefly because of late detection and inadequate treatment resources. Progressive renovations in diagnostic and management modalities of non-metastatic breast cancer (NMBC) have been noted in the region but there is paucity of data describing the clinical progress of patients with NMBC. This study sought to determine the rates of local relapse, distant metastasis and sequelae and the time span from initial treatment to the occurrence of these adverse events among patients with NMBC.

Methods: This was a retrospective review of medical records of patients with histologically confirmed NMBC at the department of radiation therapy and oncology of the Douala General Hospital in Cameroon from the January 1997 to December 2012 period. Clinicopathological and treatment characteristics as well as occurrences of adverse events were studied.

Results: A total of 260 cases were reviewed of which 224/260 (86.2\%) had invasive ductal carcinoma. Surgery was performed on 258/260 cases (99.2\%) with 187/258 (72.5\%) being modified radical mastectomies. Various treatment combinations were used in up to 228/260 patients (87.5\%) while surgery alone was the treatment in the remaining 32 cases (12.5\%). Metastasis occurred in 142/260 cases (54.6\%) of which 68/142 (26.2\%) were local relapses and 74/142 (28.5\%) were distant metastases. Among the cases of distant metastasis, $9.2 \%$ were bone, $8.5 \%$ lungs, $6.9 \%$ nodal, and $5.4 \%$ brain. Metastasis to multiple organs was noted in $4.7 \%$ of these cases. The median periods of occurrence of local relapse and distant metastases were 13 and 12 months respectively. Sequelae occurred in 26/260 cases (10\%) and were noted after an average of 30 months. The main sequelae were lymphoedema (6.5\%) and lung fibrosis (1.5\%). At the end of the period under review, 118/260 patients (45.4\%) were alive and disease-free with a median follow up time of 24 months.
\end{abstract}

Conclusions: Adverse events were frequent among patients who received primary treatment for NMBC. Available cancer therapeutic modalities ought to be supplemented with efficient strategies of follow-up and monitoring so as to optimize the care provided to these patients and improve on their survival.

Keywords: Evolution, non-metastatic, breast cancer, sub-Saharan Africa

\footnotetext{
* Correspondence: benjaminmomokadia@gmail.com

${ }^{2}$ Foumbot District Hospital, Foumbot, Cameroon

${ }^{3}$ Grace Community Health and Development Association, Kumba, Cameroon

Full list of author information is available at the end of the article
} 


\section{Background}

Breast cancer is the leading cancer among the female population in the majority of African countries [1]. More than half of women diagnosed with breast cancer in Africa die of the disease [2]. The incidence of breast cancer in Africa continues to increase and is projected to double by 2050 [3]. The rise in the rate of breast cancer has been associated with the increased prevalence of risk factors such as early menarche, late child bearing, and obesity, as well as an increase in breast cancer detection due to gradual health infrastructural development [4]. In Cameroon, the 2012 Yaounde cancer registry revealed that breast cancer accounted for about $30 \%$ of all cancers diagnosed in the community [5].

The case fatality rate of breast cancer in low and middleincome settings of sub-Saharan Africa appears to considerably exceed that in high-income countries and this is mainly as a result of advanced disease at the time of diagnosis and inadequate management resources that prevail in sub-Saharan Africa [6]. Recently, progressive refinements in breast cancer detection and treatment strategies paralleled by improvements in non-metastatic breast cancer (NMBC) management modalities have been observed in the region [7]. In Cameroon, few hospitals such as the Yaounde General Hospital and Douala General Hospital already posess multidisciplinary treatment plans [8]. Notwithstanding these advancements, NMBC patients who receive treatment are not spared of adverse events. These adverse events could be related to breast cancer itself, cancer therapy or both [9]. There is a major paucity of data regarding morbidity associated with such adverse events and it is therefore imperative to provide recent and reliable data characterizing the clinical progress of patients with NMBC after initial treatment in sub-Saharan Africa.

The objectives of this study were to determine the rates of local relapse, distant metastasis and sequelae and the time interval from initial treatment to the occurrence of these adverse events. The ultimate goal of the study is to provide data that will enable cancer treatment providers in sub-Saharan Africa to optimize the care given to patients with NMBC so as to improve on the survival of these patients.

\section{Methods}

\section{Ethical considerations}

This study was approved by the Institutional Ethics Committee for Human Health Research of the Faculty of Medicine and Pharmaceutical Sciences, University of Douala, Cameroon. Informed consent was waived by reason of the retrospective nature of the study.

\section{Study design, study period and setting}

This was a descriptive retrospective study conducted at the radiotherapy and oncology department of the Douala
General Hospital, which is a tertiary health care facility in the Littoral region in Cameroon. This hospital is one of the main tertiary healthcare facilities in the country that offers a complete treatment plan for breast cancer.

\section{Study population and sampling}

The medical records of patients with histologically diagnosed non-metastatic breast cancer (including lymphoma) from January 1997 to December 2012 were reviewed. NMBC included early breast cancer (stage 0, I, II) and locally advanced breast cancer (Stage III) cases [9].

Inclusion criteria: Patients who had complete remission after primary treatment with curative intent. Complete remission was defined as absence of symptoms and signs of breast cancer, associated normalization of radiological and biochemical indices after treatment.

Exclusion criteria: Patients whose medical records did not meet up to $90 \%$ of the information required for the study.

\section{Study procedures and variables}

The medical records of breast cancer patients treated at the radiation therapy service were retrieved and eligible cases were selected based on the predefined inclusion and exclusion criteria. A structured data collection form was used to record variables of interest. The clinicopathological data recorded per patient included demographic data: age and gender, historical data: menarche, menopausal status and parity, NMBC details: tumour size, and histological data. Treatment strategies for NMBC were categorized as surgery, radiotherapy, chemotherapy, hormone therapy, a combination of these or none. Adverse events, i.e., local relapse, distant metastasis, and sequelae after primary treatment were recorded. The follow-up period was considered as the period from diagnosis of breast cancer to the date when an adverse event was recorded. With regards to adverse events, metastatic recurrences were described as either local or distant. Local relapse (local recurrence) was defined as tumour recurrence in the ipsilateral lymph nodes (nodal recurrence), breast or chest wall while distant metastasis referred to tumour recurrence in sites remote from the breasts such as the lungs, bones, liver, and brain. Sequelae were defined as adverse events which are inherent to specific therapy, for example, lymphoedema secondary to surgical clearance of axillary lymph nodes.

\section{Statistical analysis}

Statistical analysis was done with Epi Info version 7 statistical software. Descriptive statistics were depicted using absolute numbers, percentages, ranges and means where appropriate.

\section{Reporting}

The study was reported using the STROBE guidelines. 


\section{Results}

The medical records of 568 patients diagnosed with breast cancer were reviewed amongst which 260 cases fulfilled the eligibility criteria, giving an inclusion rate of $45.8 \%$.

\section{Clinicopathological characteristics}

The ages of patients ranged from 21 to 90 years; with a mean age of $47.44 \pm 11.8$ years. Two hundred and fifty four patients $(97.70 \%)$ were females while 6 patients $(2.31 \%)$ were males. For the 254 women, the age at menarche ranged from 9 to 21 years with a mean of $13.4 \pm 2.1$ years. The majority of the women $(87.5 \%)$ had normal menarche. Gravidity varied between 0 and 13 with a median of 5.0 for the 252 women whose records had the relevant information.

Table 1 Demographic and historical characteristics of the study population

\begin{tabular}{|c|c|c|}
\hline Variable & Category & Frequency (\%) \\
\hline \multirow[t]{3}{*}{ Gender } & Female & $254(97.7)$ \\
\hline & Male & $6(2.31)$ \\
\hline & & $260(100)$ \\
\hline \multirow[t]{6}{*}{ Age at diagnosis(in years) } & $21-30$ & $15(5.8)$ \\
\hline & $31-40$ & $59(22.7)$ \\
\hline & $41-50$ & $100(38.5)$ \\
\hline & $51-60$ & $47(18.1)$ \\
\hline & $>60$ & $39(15.0)$ \\
\hline & & $260(100)$ \\
\hline \multirow[t]{4}{*}{ Age at menarche (years) } & $<11$ & $8(3.1)$ \\
\hline & $12-15$ & $222(87.5)$ \\
\hline & $>15$ & $24(9.4)$ \\
\hline & & $254(100)$ \\
\hline \multirow[t]{3}{*}{ History of contraceptive pills } & Yes & $25(9.8)$ \\
\hline & No & 229(90.2) \\
\hline & & $254(100)$ \\
\hline \multirow[t]{4}{*}{ Parity } & $\leq 1$ & $56(22.0)$ \\
\hline & $2-5$ & 115(45.3) \\
\hline & $>5$ & $83(32.7)$ \\
\hline & & $254(100)$ \\
\hline \multirow[t]{3}{*}{ Menopause at diagnosis } & Yes & $119(46.9)$ \\
\hline & No & $135(53.2)$ \\
\hline & & $254(100)$ \\
\hline \multirow[t]{3}{*}{ Breastfeeding practice } & Yes & $224(88.2)$ \\
\hline & No & $30(11.8)$ \\
\hline & & $254(100)$ \\
\hline \multirow[t]{3}{*}{ Family History of breast cancer } & Yes & 12(28.6) \\
\hline & No & $30(71.4)$ \\
\hline & & $42(100)$ \\
\hline
\end{tabular}

The entries in boldface/italics represent the total case files for which information on the relevant variable was available
Table 2 Breast cancer characteristics in study population

\begin{tabular}{|c|c|c|}
\hline Variable & Range & Frequency (\%) \\
\hline \multicolumn{3}{|l|}{ Tumour location } \\
\hline \multicolumn{3}{|l|}{ 1. Affected quadrant } \\
\hline \multicolumn{2}{|l|}{ Upper outer quadrant } & $210(82)$ \\
\hline \multicolumn{2}{|l|}{ Upper inner quadrant } & $19(7.4)$ \\
\hline \multicolumn{2}{|l|}{ Subareolar } & $14(5.5)$ \\
\hline \multicolumn{2}{|l|}{ Lower outer quadrant } & $7(2.7)$ \\
\hline \multicolumn{2}{|l|}{ Lower inner quadrant } & $6(2.3)$ \\
\hline & & $256(100)$ \\
\hline \multicolumn{3}{|l|}{ 2. Affected breast } \\
\hline \multicolumn{2}{|l|}{ Left } & $152(58.5)$ \\
\hline \multicolumn{2}{|l|}{ Right } & $107(41.2)$ \\
\hline \multicolumn{2}{|l|}{ Bilateral } & $1(0.4)$ \\
\hline & & $260(100)$ \\
\hline \multicolumn{3}{|l|}{ 3. Area of lesion } \\
\hline \multicolumn{2}{|l|}{ Unifocal } & $34(81.0)$ \\
\hline \multicolumn{2}{|l|}{ Multifocal } & $8(19.1)$ \\
\hline & & $42(100)$ \\
\hline \multicolumn{3}{|l|}{ Tumour classification } \\
\hline \multicolumn{2}{|l|}{ T0 } & $4(1.5)$ \\
\hline \multicolumn{2}{|l|}{$\mathrm{T} 1$} & $26(10.1)$ \\
\hline \multicolumn{2}{|l|}{$\mathrm{T} 2$} & $60(23.2)$ \\
\hline \multicolumn{2}{|l|}{ T3 } & $98(37.7)$ \\
\hline \multicolumn{2}{|l|}{ T4 } & $72(27.5)$ \\
\hline & $260(100)$ \\
\hline \multicolumn{3}{|l|}{ Histological type } \\
\hline \multicolumn{2}{|l|}{ Invasive ductal carcinoma } & $224(86.2)$ \\
\hline \multicolumn{2}{|l|}{ Invasive lobular carcinoma } & $12(4.6)$ \\
\hline \multicolumn{2}{|l|}{ Intraductal carcinoma } & $8(3.1)$ \\
\hline \multicolumn{2}{|l|}{ Invasive medullary carcinoma } & $6(2.3)$ \\
\hline Apocrine carcinoma & & $3(1.2)$ \\
\hline Comedo carcinoma & & $3(1.2)$ \\
\hline Lymphoma & & $1(0.4)$ \\
\hline Others & & $3(1.2)$ \\
\hline & & $260(100)$ \\
\hline Analysed lymph nodes ${ }^{a}$ & $1-5$ & $13(35.1)$ \\
\hline & $6-10$ & $12(32.4)$ \\
\hline & $11-15$ & $11(29.7)$ \\
\hline & $16-22$ & $1(2.7)$ \\
\hline & & $37(100)$ \\
\hline Positive lymph nodes ${ }^{b}$ & 0 & $5(13.5)$ \\
\hline & $1-3$ & $14(37.8)$ \\
\hline & $\geq 4$ & $18(48.6)$ \\
\hline & & $37(100)$ \\
\hline
\end{tabular}

Reported for patients with information on lymph node analysis in case file; ${ }^{\mathrm{b}}$ Positive nodes among the 37 cases with information on lymph node analysis. Mean number of positive nodes was estimated at

The entries in boldface/italics represent the total case files for which information on the relevant variable was available 
Table 3 Treatment strategies used among patients with nonmetastatic breast cancer

\begin{tabular}{|c|c|c|}
\hline Variable & Category & Frequency \\
\hline \multirow[t]{3}{*}{ Surgery } & Yes & 258(99.2) \\
\hline & No & $2(0.8)$ \\
\hline & & $260(100)$ \\
\hline \multirow[t]{3}{*}{ Type of surgery } & Radical mastectomy & $187(72.5)$ \\
\hline & $\begin{array}{l}\text { Breast conserving } \\
\text { surgery }\end{array}$ & $71(27.5)$ \\
\hline & & $258(100)$ \\
\hline \multirow{3}{*}{$\begin{array}{l}\text { *Axillary lymph } \\
\text { node dissection }\end{array}$} & Yes & 210(81.4) \\
\hline & No & $48(18.6)$ \\
\hline & & $258(100)$ \\
\hline \multirow[t]{3}{*}{ Chemotherapy } & Yes & $147(56.5)$ \\
\hline & No & $113(43.5)$ \\
\hline & & $260(100)$ \\
\hline \multirow[t]{4}{*}{ Type } & Neoadjuvant & $14(9.5)$ \\
\hline & Adjuvant & 107(72.8) \\
\hline & Both & $26(17.7)$ \\
\hline & & $147(100)$ \\
\hline \multirow[t]{5}{*}{ Drug combination } & $\begin{array}{l}\text { Cyclophosphamide + } \\
\text { Doxorubicin + } \\
\text { 5-Fluorouracil }\end{array}$ & $120(82)$ \\
\hline & $\begin{array}{l}\text { Cyclophosphamide + } \\
\text { Methotrexate + } \\
\text { 5-Fluorouracil }\end{array}$ & $7(4.8)$ \\
\hline & $\begin{array}{l}\text { Docetaxel }+ \\
\text { Doxorubicin }+ \\
\text { Cyclophosphamide }\end{array}$ & $4(2.7)$ \\
\hline & OTHERS & 16(10.8) \\
\hline & & $147(100)$ \\
\hline \multirow[t]{2}{*}{ Hormone therapy } & Yes & 129(49.8) \\
\hline & No & $131(50.4)$ \\
\hline \multirow[t]{3}{*}{ Type } & Anastrozole & $7(5.4)$ \\
\hline & Tamoxifen & 122(94.6) \\
\hline & & $129(100)$ \\
\hline Duration & $5 y e a r s$ & $13(100)$ \\
\hline \multirow[t]{3}{*}{ Radiation therapy } & Yes & $201(77.3)$ \\
\hline & No & $59(22.7)$ \\
\hline & & $260(100)$ \\
\hline \multirow[t]{4}{*}{ Duration } & 5 weeks & 178(88.6) \\
\hline & 6 weeks & $20(10.0)$ \\
\hline & 9 weeks & $2(1.0)$ \\
\hline & 10 weeks & $1(0.5)$ \\
\hline
\end{tabular}

Treatment combination

Surgery + chemotherapy + radiation therapy
Table 3 Treatment strategies used among patients with nonmetastatic breast cancer (Continued)

\begin{tabular}{|c|c|c|}
\hline Variable & Category & Frequency (\%) \\
\hline $\begin{array}{l}\text { Surgery }+ \text { chemotherapy }+ \\
\text { radiation therapy }+ \\
\text { hormonal therapy }\end{array}$ & & 63(24.1) \\
\hline $\begin{array}{l}\text { Surgery + radiation therapy }+ \\
\text { hormonal therapy }\end{array}$ & & $50(19.5)$ \\
\hline Surgery alone & & $32(12.5)$ \\
\hline Surgery + radiation therapy & & $20(7.8)$ \\
\hline Surgery + chemotherapy & & $12(4.7)$ \\
\hline Surgery + hormonal therapy & & $11(3.9)$ \\
\hline \multirow[t]{2}{*}{$\begin{array}{l}\text { Surgery + chemotherapy + } \\
\text { hormonal therapy }\end{array}$} & & $6(2.0)$ \\
\hline & & $260(100)$ \\
\hline
\end{tabular}

The entries in boldface/italics represent the total case files for which information on the relevant variable was available

Parity ranged from 0 to 11 , with a mean of $4.2 \pm 2.8$. Breastfeeding was practiced in $88.2 \%$ of all the women, with the duration ranging from 3 to 18 months postpartum. Menopause was reported in 119/254 women (46.9\%) at the time of diagnosis. The demographic and historical characteristics of the study population are summarized on Table 1.

The left breast was affected in 152/260 (58.5\%) of the cases compared with $107 / 260$ (41.2\%) for the right breast. Among the 256 cases with records on breast cancer location, the upper outer quadrant of the breast was involved in as many as $210(82 \%)$, while only $6(2.3 \%)$ had an affected lower inner quadrant. Relevant information on the topography of the lesions on the breast was available for 42 patients among whom 34/42 (81.0\%) had unifocal lesions while multifocal lesions were noted in $8 / 42$ (19.1\%). Locally advanced (T3 and T4) breast cancer was noted in up to 170 (65.4\%) of the 260 cases included. Invasive ductal carcinoma was the histological diagnosis in up to $224 / 260(86.5 \%)$ of all cases. The clinicopathological characteristics of our cohort are summarized on Table 2.

\section{Treatment modalities}

Surgery was performed on 258/260 (99.2\%) of the patients. Up to $187 / 258$ (72.5\%) of these patients underwent modified radical mastectomy. Chemotherapy was employed in $147 / 260(56.5 \%)$ of the cohort and was adjuvant in 107 cases $(72.8 \%)$. Of the 260 patients included, 129 (49.8\%) effectively used hormone therapy. Amongst these, there were 13 patients $(10 \%)$ who had completed cancer treatment and had used hormone therapy within a period of 5 years while the other 116 patients (90\%) were still on hormone therapy during the period under study. Radiation therapy was delivered by a cobalt unit and was used in up to $201 / 260(77.3 \%)$ in the postoperative period. The dose of 50 Gy over a mean duration of 5 weeks \pm 0.6 was given for 
most mastectomy patients when indicated. A dose of 50Gy over a 5 weeks period with a booster dose of 10Gy to the tumor site was administered if the histopathological analysis revealed positive surgical margins. The most frequent combination therapy was surgery, chemotherapy and radiation therapy which was employed in $66 / 260$ cases $(25.7 \%)$. This was closely followed by the combination of surgery, chemotherapy, radiation therapy and hormone therapy which was used in 62/260 cases (24.1\%). Table 3 summarizes the treatment characteristics in our cohort.

\section{Clinical progress of the study population}

Table 4 describes the clinical progress of the study population. The median follow up period was 24 months (range: 3 months to 168 months). Overall, recurrences were noted in as many as $142 / 260$ cases (54.6\%). Amongst these, 68 (26.2\%) developed local recurrences that were noted between 1 to 120 months (median recurrence time of 13 months) and 74 (28.5\%) developed distant metastases that were noted between 1 month to 108 months (median time of 12 months) after initial

Table 4 Clinical progress of study population

\begin{tabular}{ll}
\hline Adverse event & Frequency (\%) \\
\hline Local recurrence & $68(26.2)$ \\
Distant metastases & $74(28.5)$ \\
All cases of recurrence & $142(54.6)$ \\
Total case files included & $260(100)$ \\
Sites of recurrence & \\
Chest wall & $68(26.2)$ \\
Brain & $14(5.4)$ \\
Bone & $24(9.2)$ \\
Liver & $7(2.7)$ \\
Lung & $22(8.5)$ \\
Lymph nodes & $18(6.9)$ \\
Bone and brain & $2(0.8)$ \\
Bone and lung & $5(1.9)$ \\
Liver and lung & $1(0.4)$ \\
Brain and lung & $3(1.2)$ \\
Brain and liver & $1(0.4)$ \\
4. Dequelae & $1(0.4)$ \\
\hline
\end{tabular}

treatment. During follow up, 24/260 patients (9.2\%) developed bone metastasis followed by lung metastasis in $22 / 260$ cases $(8.5 \%)$, brain metastasis in $14 / 260$ cases (5.4\%) and liver metastasis in a small minority of $7 / 260$ cases (2.7\%). Nodal metastasis was noted in $18 / 260$ cases (6.9\%). A few cases (4.7\%) developed metastasis to multiple organs. As concerns metastasis to bone, recurrences were observed between 1 to 60 months (median period of 12 months) after initial treatment. As concerns lung metastasis, the time between initial treatment and occurrence of metastasis ranged from 1 to 72 months with a median period of 20 months. The time elapse between initial treatment and the occurrence of brain metastasis ranged from 3 months to 36 months (median period of recurrence of 12 months). In relation to liver metastasis, its occurrence was noted between 2 to 108 months (median period of 40 months) after initial treatment. The time intervals between primary treatment and metastatic recurrences are summarized on Table 5.

Sequelae were recorded in $26 / 260$ cases (10\%). The time elapased between initial treatment and occurrence of sequelae ranged from 1 to 48 months (Table 6) with a mean period of 30 months. Lymphoedema was the most frequent late complication and occurred in 17/260 cases (6.5\%). The swelling due to lymphoedema was noted after an average period of 16 months with the period of occurrence after treatment ranging from 1 to 36 months. Lung fibrosis was the second most common sequela and was noted in 4 cases (1.5\%). It occurred on average 22 months after initial treatment.

At the end of the period under review, 118/260 patients (45.4\%) were alive and disease-free with a median follow up time of 24 months range (3 months to 168 months). We noted that $109 / 260$ patients (41.9\%) were followed-up for 12 months or less as shown on Table 7 .

A comparative table (Table 8) summarizes our main findings and compares these findings with those of some previous studies assessing the clinical progress of patients with NMBC within and outside Africa.

\section{Discussion}

African countries are characterized by extreme paucity of reports on the morbidity of NMBC following various available treatment modalities [6]. This study is one of the rare assessing the outcome of NMBC in sub-Saharan Africa in an era of progressive health infrastructural development [7]. The study contributes to solving the problem of alarming lack of data and guidelines on cancer treatment in sub-Saharan Africa where the incidence of breast cancer is on the rise.

Our study revealed that patients with non-metastatic breast cancer were relatively young and this reflects the usual early age of onset of breast cancer among black Africans. Although the reason for this is poorly elucidated, it has been 
Table 5 Time interval between initial treatment and occurrence of metastases

\begin{tabular}{|c|c|c|c|}
\hline Type of metastasis & Interval (months) & Frequency & Percentage \\
\hline \multirow[t]{7}{*}{ Local recurrence } & $0-12$ & 38 & 55.9 \\
\hline & $13-24$ & 13 & 19.1 \\
\hline & $25-36$ & 4 & 5.9 \\
\hline & $37-48$ & 4 & 5.9 \\
\hline & $49-60$ & 3 & 4.4 \\
\hline & $>60$ & 6 & 8.8 \\
\hline & & 68 & 100 \\
\hline \multirow[t]{7}{*}{ Distant metastasis } & $0-12$ & 37 & 50 \\
\hline & $13-24$ & 17 & 23 \\
\hline & $25-36$ & 10 & 13.5 \\
\hline & $37-48$ & 4 & 5.4 \\
\hline & $49-60$ & 4 & 5.4 \\
\hline & $>60$ & 2 & 2.7 \\
\hline & & 74 & 100 \\
\hline \multirow[t]{4}{*}{ Brain metastasis } & $0-12$ & 7 & 50 \\
\hline & $13-24$ & 3 & 21.4 \\
\hline & $25-36$ & 4 & 28.6 \\
\hline & & 14 & 100 \\
\hline \multirow[t]{6}{*}{ Bone metastasis } & $0-12$ & 15 & 62.5 \\
\hline & $13-24$ & 6 & 25 \\
\hline & $25-36$ & 2 & 8.3 \\
\hline & $37-48$ & 0 & 0 \\
\hline & $49-60$ & 1 & 4.2 \\
\hline & & 24 & 100 \\
\hline \multirow[t]{7}{*}{ Lung metastasis } & $0-12$ & 9 & 40.9 \\
\hline & $13-24$ & 6 & 27.3 \\
\hline & $25-36$ & 3 & 13.6 \\
\hline & $37-48$ & 1 & 4.5 \\
\hline & $49-60$ & 2 & 9.1 \\
\hline & $>60$ & 1 & 4.5 \\
\hline & & 22 & 100 \\
\hline \multirow[t]{7}{*}{ Liver metastasis } & $0-12$ & 3 & 42.9 \\
\hline & $13-24$ & 1 & 14.3 \\
\hline & $25-36$ & 0 & 0 \\
\hline & $37-48$ & 0 & 0 \\
\hline & $49-60$ & 1 & 14.3 \\
\hline & $>60$ & 2 & 28.6 \\
\hline & & 7 & 100 \\
\hline
\end{tabular}

Table 5 Time interval between initial treatment and occurrence of metastases (Continued)

\begin{tabular}{llll}
\hline Type of metastasis & Interval (months) & Frequency & Percentage \\
\hline Nodal metastasis & $0-12$ & 8 & 44.4 \\
& $13-24$ & 4 & 22.2 \\
& $25-36$ & 4 & 22.2 \\
& $37-48$ & 2 & 11.1 \\
& & $\mathbf{1 8}$ & $\mathbf{1 0 0}$
\end{tabular}

The entries in boldface/italics represent the total case files for which information on the relevant variable was available

suggested that breast cancer seems to have a more aggressive propensity and consequently manifests earlier in Americans of black African descent [16]. Most patients in our study had invasive ductal carcinoma and this corroborates with the findings of previous reports from Africa [17-21]. Surgery remained the mainstay of treatment in our review and was typically non-conservative because of the prevailing locallyadvanced breast cancer which may have been consequent to factors such as inadequate self-breast examination, poverty leading to delayed medical care, prolonged denial after diagnosis, fear of disfigurement from surgery and preferred alternative medicine [22]. The documented number of positive lymph nodes extracted during the surgical procedures was substantial and comparable to that of a previous report carried out in an urban setting like ours [20]. Albeit such extensive rates of positive lymph nodes could be accounted for by large tumour sizes at diagnosis as well as the aggressive variant and poor histological differentiation of breast cancer in most of the patients, it is worth noting that lymph node dissection and analysis in our setting was generally done for cases with clinical suspicion of advanced disease. This may have induced a bias towards overestimation of the pathological incidence of positive lymph nodes. Combinations of various treatment options were used in a greater majority of our cohort. Overall, after initial treatment, metastatic recurrences were frequent, even though most were local recurrences. Distant metastases usually affected bones and the lungs. Metastatic recurrences generally occurred few months after initial treatment contrary to the less observed sequelae that generally occurred much later and were mainly accounted for by lymphoedema and lung fibrosis.

The highest proportion of metastatic recurrences were observed within the first 24 months after primary treatment, which is fairly similar to the results obtained by Noufel et al. who observed the highest proportion of recurrences between 12 and 19 months [23]. Also, Donnelly et al. reported that median time to presentation of recurrence was 19 months for metastatic and 18 months for locoregional disease [24]. Chauleur et al. in France found that the period of observation for local recurrence ranged from 4 to 36 months, while distant metastatis ranged from 9 to 24 months [25]. While noting the relatively short median period of development of specific organ metastasis observed in our study, the findings 
Table 6 Time interval between initial treatment and occurrence of various sequelae

\begin{tabular}{lll}
\hline Variable & Period (months) & Frequency(Percentage of total) \\
\hline Arm edema & $<12$ & $10(58.8)$ \\
& $12-24$ & $4(23.5)$ \\
& $25-36$ & $3(17.6)$ \\
& & $\mathbf{1 7}(100)$ \\
Lung fibrosis & $<6$ & $2(50)$ \\
& $6-12$ & $1(25)$ \\
& $>12$ & $1(25)$ \\
Radiodermatitis & 7 & $\mathbf{4 ( 1 0 0 )}$ \\
Lung telangiectasia & 24 & $\mathbf{1 ( 1 0 0 )}$ \\
Nervous plexopathy & 12 & $\mathbf{1 ( 1 0 0 )}$ \\
Skin fibrosis & 12 & $\mathbf{1 ( 1 0 0 )}$ \\
Rib fracture & 24 & $\mathbf{1 ( 1 0 0 )}$ \\
\hline
\end{tabular}

The entries in boldface/italics represent the total case files for which information on the relevant variable was available

in these reports and our review indicate the need to implement closer follow-up strategies especially during the first twenty four months after primary treatment since this is the period when recurrences tend to occur irrespective of the income setting. It was also noted that a considerable proportion of patients in our review presented for follow up only during the first 12 months after treatment. Aside poverty and ignorance of the seriousness of the disease, this phenomenon could be explained by the fact that after initial treatment, patients may underestimate the possibility of adverse events. This phenomenon further highlights the necessity to strengthen patient education, follow-up strategies and means of recapturing lost to follow up cases after primary treatment of NMBC.

Local recurrence was noted in $26.2 \%$ of our cases, a figure which is higher than those previously reported in low-income settings of Nigeria by Elumelu et al. (16\%), Ethiopia by Ersumo et al. (15\%), Afghanistan by Noufel et al. (7\%), and India by Raina et al. (2.7\%) [21, 23, 26, 27]. While the high rate of local recurrence in our study

Table 7 Durations of follow-up among patients with non-metastatic breast cancer

\begin{tabular}{lll}
\hline Interval & Frequency & Percentage \\
\hline $0-12$ & 109 & 41.9 \\
$13-24$ & 64 & 24.6 \\
$25-36$ & 26 & 10.0 \\
$37-48$ & 18 & 6.9 \\
$49-60$ & 17 & 6.5 \\
$>60$ & 26 & 10.0 \\
Total & 260 & 100 \\
\hline
\end{tabular}

may be attributed to prevalent locally-advanced breast cancer and possibly non-adherence to adjuvant treatment which is known to significantly limit locoregional recurrence, it is worth noting that there were wide variations in sample sizes, clinico-pathological characteristics, treatment modalities and durations of follow-up in all the studies. These may account for the differences in the rates of local recurrences. The fair comparability in the rates of local recurrence in our report, that of Elumelu et al. in Nigeria and Ersumo et al. in Ethiopia, may be attributed to the similar ethnic and clinico-pathological characteristics as well as similar durations of follow-up of the study populations.

The proportion of patients with early breast cancer who develop distant metastases generally varies $15 \%$ to $25 \%$ at 5 years regardless of surgical technique [28]. In our report, the rate of distant metastasis was up to $28.5 \%$ which is relatively high in comparison to what was reported in a previous study carried out in sub-Saharan Africa [29]. Apart from the high rate of locally-advanced tumour and the invasive nature of the histological type of breast cancer found in most of our patients, this observation could also be associated with the predilection of breast cancer for the upper outer quadrant in our study population. This quadrant is in close proximity to the axillary tail which is a more frequent channel for metastases when compared with the other quadrants of the breast $[29,30]$. In spite of significant variations in reported rates, bones and lungs are generally the most frequent sites of distant metastasis in patients with breast cancer [31]. A previous study in Pennsylvania detected bone metastasis in up to $40 \%$ of a cohort of breast cancer patients [32] probably due to the longer follow-up period and better diagnostic resources.

The rate and mean period of occurrence of sequelae in our study is almost equivalent to what was reported by Hagigat et al. in Iran and Pawlaczyk et al. although they noted prevalence rates as high as $31.7 \%$ [33] and 22\% [34] respectively. Furthermore, Kornblith et al. reported a prevalence rate of sequelae of up to $39 \%$ twenty years after the initial treatment [35]. Even though Hagigat et al. explained that postoperatively most patients usually limit movement of the surgical site which can induce lymphoedema [33] (the most frequent sequela in our study and previous reports), the relatively high rates of sequelae noted in these studies could be attributed to the longer follow-up periods and invariably lower rates of lost to follow-up which permitted detection of more sequelae.

The current report is not void of limitations. There was a possibility of selection bias given its retrospective singlecenter design. It is also worth mentioning that the stringent nature of our selection criteria resulted in a considerably low inclusion rate which was, nonetheless, necessary for reliable results to be generated from the poorly archived 
Table 8 Comparison of main findings of studies assessing the clinical progress of patients treated for non-metastatic breast cancer Main findings

\begin{tabular}{lll}
\hline $\begin{array}{l}\text { Authors and } \\
\text { location }\end{array}$ & Investigation & $\begin{array}{l}\text { Study design and } \\
\text { study population }\end{array}$ \\
\hline $\begin{array}{l}\text { Millar et al. } 2009 \text {, Australia [10] } \\
\text { Prediction of LR, DM, and Death After } \\
\text { Breast-Conserving Therapy in Early-Stage } \\
\text { Invasive Breast Cancer Using a 5-Biomarker } \\
\text { Panel }\end{array}$ & $\begin{array}{l}\text { Randomized clinical } \\
\text { trial:498 cases }\end{array}$ \\
$\begin{array}{ll}\text { Diniz et al. 2016, } \\
\text { Brazil (South America) [11] }\end{array}$ & Disease-free survival in patients with & $\begin{array}{l}\text { Three-year retrospective } \\
\text { NMBC }\end{array}$ \\
$\begin{array}{ll}\text { Budakoglu et al. 2014, } \\
\text { Turkey (Eurasia) [12] }\end{array}$ & Outcome of triple negative NMBC patients & $\begin{array}{l}\text { cases } \\
\text { Eleven-year multi-center } \\
\text { retrospective study:561 }\end{array}$ \\
& & cases
\end{tabular}

Median follow-up: 84 months. Ipsilateral breast tumour recurrence:24 (4.8\%), LR:35 (7\%), DM:47 (9.4\%), and cancer deaths:37 (7.4\%). Overall 5-year disease-free rates: ipsilateral breast tumour recurrence,97.4\%; LR,95.6\%; DM: 92.9\%, and cancer-specific death:96.3\%. Significant difference in survival between subtypes (of invasive breast cancer) for $L R, D M$ and breast cancer-specific death

Disease recurrence noted in 129 cases:17.8\% LR; $54.3 \%$ DM and $27.9 \%$ died. Disease free survival at 5 years:72\%

Ratio of triple-negative breast cancer:12\%. Median patient follow-up was 28 months (range 3-290). Most commonly variant was invasive ductal carcinoma (84.1\%). Grade II and III tumours were 27.1 and $48.5 \%$, respectively. DM occurred in $134(23.8 \%)$ patients and was mainly to bone, soft tissue, and lung. Factors affecting DFS and OS: age, lymph node involvement, lymphovascular invasion, tumour stage, adjuvant anthracycline-based chemotherapy and type of surgery (not significant for DFS). Three-year DFS and OS:72.0 and $93.0 \%$, respectively

The median follow-up: 4.4 years. Recurrence following primary treatment was seen in $35 \%$ of the patients: $5 \%$ local, 1\% regional, and 29\% distant. At time of last follow-up: 960 patients were dead and 1869 (66\%) were alive of which 112 were alive with disease. Cause of dead: breast cancer in 922 patients, treatment related toxicity in 8 patients and non-cancer related in 30 patients.

Age at diagnosis in women with NMBC Is it related to prognosis?

One-year single-center retrospective study:941 cases

Most presented with advanced disease. All relapse: $44.2 \%$; DM: 33.5\%; LR: 6.6\%. Women below 40 years of age had higher recurrence rates and poorer prognosis

Do younger women with non-metastatic non-inflammatory breast carcinoma have poor prognosis?

Ten-year single-center prospective study:1701 cases

Median follow-up period: 66 months. Six hundred and forty (38\%) were dead while 556 were not cured. Of the 556 patients, 125 (22.4\%) had metastasis in bone (7.1\% spine), 41 (7.3\%) in liver, $40(7.1 \%)$ in lung, $34(6.1 \%)$ in brain, 20 (3.5\%) in opposite breast and 169 (30.3\%) had multiple metastasis. Women $<40$ years with $\mathrm{T} 3 / \mathrm{T} 4$ breast lesions and/or positive axillary nodes had a significantly poorer survival

Sixteen-year single-center retrospective study:260

Median follow up period: 24 months. Majority of patients had invasive ductal carcinoma. Metastases occurred in 142/260 (54.6\%): 68/142 (26.2\%) LR and 74/142 (28.5\%) DM. DM: $9.2 \%$ bone, $8.5 \%$ lungs, $6.9 \%$ nodal, and $5.4 \%$ brain; $4.7 \%$ multiple metastasis. Median periods of occurrence of LR and DM: 3 and 12 months respectively. Sequelae were noted in 26/260 (10\%), after an average of 30 months. Main sequelae: lymphedema $(6.5 \%)$ and lung fibrosis (1.5\%). At the end of review period, 118/260 patients (45.4\%) were alive and disease-free. medical records in our context. Furthermore, our study like most from Africa, focused on describing morbidity data and lacked direct survival analysis. Nonetheless, we were able to derive that less than half of the patients were alive and disease-free at the end of the review period, albeit the individual follow-up periods were regrettably short in a significant proportion of the patients.

\section{Conclusions}

Despite progressive health infrastructural development in sub-Saharan Africa, our study reveals that adverse events were frequent and occurred relatively early among patients who received primary treatment for NMBC during the 16 year period from 1997 to 2012 at the Douala General Hospital in Cameroon. The available cancer therapeutic modalities in this setting ought to be supplemented with guidelines on efficient strategies of follow-up and monitoring so as to optimize the care provided to these patients and ultimately improve on their survival. For these to be achieved, further studies on prognostic features of patients receiving primary treatment for NMBC in the sub-Saharan African context may be warranted.

\section{Abbreviation}

NMBC: Non-metastatic breast cancer

\section{Acknowledgements}

We thank the staff of the radiation therapy and oncology department of the Douala General Hospital for ensuring the conducive environment in which this research was conducted.

\section{Funding}

This research received no funding support. 


\section{Availability of data and materials}

The datasets used and/or analysed during the current study are available from the corresponding author on reasonable request.

\section{Authors' contributions}

BAN and MEB conceived the study, organized the research material, collected the data and wrote the initial manuscript. BMK and NNB performed the literature search, conducted the data analysis, interpreted the data and prepared the final manuscript. CAD: Participated in drafting the manuscript. He also reviewed the scientific content of the paper and edited the final manuscript. AMS: Assited in collecting and interpreting the data. He provided technical and intellectual guidance and acted as the overall supervisor of the study. All the authors read and approved the final manuscript.

\section{Ethics approval and consent to participate}

Ethical registry (Reference number: 81/UD/FMSP/2014) was obtained from the Institutional Ethics Committee for Human Health Research of the Faculty of Medicine and Pharmaceutical Sciences, University of Douala, Cameroon. Informed consent was waived by reason of the retrospective nature of the study.

\section{Consent for publication}

Not applicable.

\section{Competing interests}

The authors declare that they have no competing interests.

\section{Publisher's Note}

Springer Nature remains neutral with regard to jurisdictional claims in published maps and institutional affiliations.

\section{Author details \\ ${ }^{1}$ Faculty of Medicine and Pharmaceutical Sciences, University of Douala, Douala, Cameroon. ${ }^{2}$ Foumbot District Hospital, Foumbot, Cameroon. ${ }^{3}$ Grace Community Health and Development Association, Kumba, Cameroon. ${ }^{4}$ Faculty of Health Sciences, University of Buea, Buea, Cameroon. ${ }^{5}$ School of Health Sciences, University of Nottingham, Nottingham, UK. ${ }^{6}$ Health and Human Development (2HD) Research Network, Douala, Cameroon. ${ }^{7}$ Faculty of Epidemiology and Population Health, London School of Hygiene and Tropical Medicine, London, UK. ${ }^{8}$ Department of Orthopaedics, Southend University Hospital, Essex, UK.}

\section{Received: 13 June 2017 Accepted: 27 December 2017}

\section{Published online: 05 January 2018}

\section{References}

1. Kantelhardt EJ, Cubasch H, Hanson C. Taking on breast cancer in East Africa: global challenges in breast cancer. Curr Opin Obstet Gynecol. 2015;27:108-14.

2. Ginsburg OM. Breast and cervical cancer control in low and middle-income countries: human rights meet sound health policy. J Cancer Policy. 2013;1:e35-41.

3. Chokunonga E, Borok MZ, Chirenje ZM, Nyakabau AM, Parkin DM. Trends in the incidence of cancer in the black population of Harare, Zimbabwe 1991- 2010. Int J Cancer. 2013;133:721-9.

4. Jemal A, Bray F, Forman D. O1'Brien M, Ferlay J, center M, Parkin DM Cancer burden in Africa and opportunities for prevention. Cancer. 2012; 118(18):4372-84.

5. Enow-Orock G, Ndom P, Doh AS. Current cancer incidence and trends in Yaounde. Cameroon Oncol Gastroenterol Hepatol Rep. 2012;1(1):58-63.

6. Pace LE, Shulman LN. Breast cancer in sub-Saharan Africa: challenges and opportunities to reduce mortality. Oncologist. 2016;21(6):739-44.

7. Schmitz KH, Speck RM, Rye SA, DiSipio T, Hayes SC. Prevalence of breast cancer treatment sequelae over 6years of follow up. Cancer. 2012;118(8):2217-25

8. Nguefack CT, Biwole ME, Massom A, Kamgaing JT, Njamen TN, Ekane GH, et al. Epidemiology and surgical management of breast cancer in the gynecological Department of Douala General Hospital. Pan Afr Med J. 2012;13:35.

9. Abdulhadi TJ. Non metastatic breast cancer: clinical presentation and patterns of surgical treatment. Al Kindy Col Med J. 2009;5(1):40-6.

10. Millar EKA, Graham PH, O'Toole SA, McNeil CM, Browne L, Morey AL, et al. Prediction of local recurrence, distant metastases and death after breastconserving therapy in early-stage invasive breast cancer using a fivebiomarker panel. J Clin Oncol. 2009;27:4701-8.
11. Diniz RW, Guerra MR, Cintra JRD, Fayer VA, Teixeira MTB. Disease-free survival in patients with non-metastatic breast cancer. Rev Assoc Med Bras. 2016;62(5):407-13

12. Budakoglu B, Altundag K, Aksoy S, Kaplan MA, Ozdemir NY, Berk V, et al. Outcome of 561 non-metastatic triple negative breast cancer patients: multicenter experience from Turkey. J BUON. 2014;19(4):872-8.

13. Jamshed A, Shah MA, Syed AA, Murtaza G, Mehmood T, Chaudry SA, et al. Clinical outcome of primary non-metastatic breast cancer: a single institution experience. Indian J Cancer. 2015;52:119-25.

14. Alieldin NH, Abo-Elazm OM, Bilal D, Salem SE, Gouda E, Elmongy M, et al. Age at diagnosis in women with non-metastatic breast cancer. Is it related to prognosis? J Egypt Natl Canc Inst. 2014;26:23-30.

15. Mathew A, Rajan B, Panday M. Do younger women with non-metastatic and non-inflammatory breast carcinoma have poor prognosis? World J Surg Oncol. 2004:2:2

16. Danforth JDN. Disparities in breast cancer outcomes between Caucasian and African American women: a model for describing the relationship of biological and nonbiological factors. Breast Cancer Res. 2015;15:208.

17. Popoola AO, Ibrahim NA, Omodele FO, Oludara MA, Adebowale SA, Igwilo Al. Pattern of spread of breast cancer among patients attending cancer unit of Lagos state university teaching hospital. Asian J Med Sci. 2012;4(3):89-94.

18. Ohene-Yaboah M, Adjei E. Breast cancer in Kumasi. Ghana Ghana Med J. 2012;46(1):8-13

19. Ogundiran OT, Ayandipo OO, Ademola AF, Adebamowo CA. Mastectomy for management of breast cancer in Ibadan. Nigeria BMC Surg. 2013;13:59.

20. Essiben F, Foumane P, Mboudou ET, Dohbit JS, Mve Koh V, Ndom P. Diagnosis and treatment of breast cancer in Cameroon: A series of 65 cases. Mali Medical. 2013:28:1-5.

21. Elumelu TN, Adenipekun AA, Abdusalam AA, Bojude AD. Pattern of breast cancer metastasis at the radiatiotherapy clinic, Ibadan. A ten year review. Am Sci. 2011;7(7):906-12.

22. Donkor A. Factors contributing to late presentation of breast cancer in Africa: a systematic literature review. Arch Med. 2015:8:2.

23. Noufel SM, AL-mukhtar R, Al-Dawoodi NS, Sulaiman TI. Recurrent breast cancer following modified radical mastectomy and risk factors. J Fac Med Baghdad. 2012;54(3):198-203.

24. Donnelly J, Mack P, Donaldson LA. Follow up of breast cancer: time for a new approach? Int J Clin Pract. 2001;55(7):431-3.

25. Chauleur C, Vulliez L, Trombert B, Raoux D, Khaddage A, Seffert P. Facteurs de risque de récidive des cancers du sein traités par chirurgie conservatrice: a propos de 254 cas. J Gynecol Obstet Biol Reprod. 2008;37:170-8.

26. Ersumo T. Breast cancer in an ethiopian population, Addis Ababa. East and Central Afr J Surg. 2006;11(1):81-6.

27. Raina V, Bhutani M, Bedi R, Sharma A, Deo Suryanarayana VS, Shukla NK, et al. Clinical features and prognostic factors of early breast cancer at a major cancer center in North India. Indian J Cancer. 2005:42(1):36-41.

28. Elder EE, Kennedy CW, Gluch L, Carmalt HL, Janu N, Joseph MG et al. patterns of breast cancer relapse. Eur J Surg Oncol 2006; 32(9): 922-927.

29. Mabula JB, Mabula MD, Chalya PL, Giiti G, Chandika AB, Rambau P, et al. Stage at diagnosis, clinicopathological and treatment patterns of breast cancer at Bugando medical center in north western Tanzania. Tanzan J Health Res. 2012;14(4):1-14.

30. Kene TS, Odigie VI, Yusufu LMD, Shehu SM, Kase JT. Pattern of presentation and survival of breast cancer in a teaching Hospital in North Western Nigeria. Oman Med J. 2010;25:104-7.

31. Manders K, Van de Poll-Franse LV, Creemers GJ, Vreugdenhil G, Van der Sangen MJ, Nieuwenhuijzen GA, et al. Clinical management of women with metastatic breast cancer: a descriptive study according to age group. BMC Cancer. 2006:6:179.

32. Berman AT, Thukral AD, Wei-Ting H, Solin L, Vapiwala N. Incidence and patterns of distant metastasis for patients with early stage breast cancer after breast conservation treatment. Clin Breast Cancer. 2013;13(2):88-94.

33. Shahpar H, Atieh A, Maryam A, Fatemeh HS, Massoome N, Mandana E et al. Risk factors of lymph edema in breast cancer patients. Int J Breast Cancer 2013; 2013: 641818 doi.org/https://doi.org/10.1155/2013/641818

34. Anna P. An analysis of long term complications in breast cancer patients after conservative therapy. Rep Pract Oncol Radiother. 2006;11(2):81-9.

35. Kornblith AB. Herndon $11 \mathrm{JE}$, Weiss RB, Zhang C, Zuckerman EL, Rosenberg $S$ et al.Long-term adjustment of survivors of early-stage breast carcinoma, 20years after adjuvant chemotherapy. Cancer. 2003;98(4):679-89. 